\title{
Establishing the Boundaries and Building Bridges: Research Methods Into the Ecology of the Refugee Parenting Experience
}

\author{
Nombasa Williams
}

\begin{abstract}
This article discusses the suitability of the focus group method for conducting research early in post-resettlement among refugee parents and carers in South Australia. This method was employed to uncover the refugee parenting experience in pre-resettlement contexts. There were three refugee focus groups, consisting of a Sudanese women's group, an African men's group, and an Afghani and Iraqi women's group. To illustrate each group's differential parenting ecologies in milieus of forced migration ecological matrixes were devised which are presented in the results section. An ecological matrix was also developed to unpack, code and analyse transcripts. The matrix was designed to include categories and actions so as to construct meaning units and subsequent condensed meaning units to determine the concluding themes. These provided an analytical framework with which to illuminate the constructed meanings participants attributed to their refugee parenting experiences. The findings provide insights into the ecology of the refugee parenting experience and might be of considerable importance for Australian resettlement services and state systems of child protection seeking to develop culturally appropriate and relevant services.
\end{abstract}

Key words: Refugee parents, ecology, focus group interview, parenting experiences, child protection

Please cite this article as:

Williams, N. (2010). Establishing the Boundaries and Building Bridges: Research Methods Into the Ecology of the Refugee Parenting Experience. Qualitative Studies, 1(2): 91-114.

There is a lack of research that describes the ecology of the refugee parenting experience in preresettlement contexts. The research method, design and rationale of this study were developed to inform why refugee families are presenting within the South Australian system of child protection. The purpose of this paper is two-fold: first, to discuss the suitability of the focus group method for resettled refugee participant research, and why this method was employed in this study to access the meanings, language and concepts adopted by refugees to make sense of their parenting experiences in pre-resettlement contexts; and, second, to present the analytical framework devised to shape participant discussions for transcript coding. The findings might be of considerable importance to Australian resettlement programs in the planning and development of culturally appropriate and relevant services centred on child protection (see also Department of Immigration and Citizenship, 2007; Lewig et al., 2009).

Past research efforts into refugees have primarily focused on the drivers that determine the political conditions that create a refugee situation; the economic impact of conflict and war; the disruption of cultural norms and values; the displacement of social organisation (such as marital practices) and family structures (including gender roles); shifts in power driven by an increase in the impact of external factors relative to that of internal factors; or on analyses of the efficacy of resettlement schemes (Indra, 1999; Wiseman \& Khan, 1995; Ye-Chin, 1980). There are theoretical and analytical 
gaps in the literature because of the lack of empirical research around the refugee parenting experience. The research method utilised in this study illuminated the ecology of the refugee parenting experience of focus group participants within pre-resettlement contexts and subsequently identified the meanings and understandings attributed by participants to their experiences. Recognising the influence of cultural beliefs, norms and values, as well as that of the particular conditions within each refugee camp, and the mediating role each of these factors plays, this study sought to discern common patterns and themes that reflect and describe how parents cope with the changing spaces of crisis, flight and migration. Very little empirical research has been conducted in the area of the ecology of the refugee parenting experience that actually describes experiences through the voices of refugees themselves. Practice wisdom, urban myths and unfounded assumptions abound regarding what ordinary people face in extraordinary circumstances, yet very little is known about the day-to-day experiences of refugees or how the environment of flight and migration affects the parenting process for families and carers.

The fact that alterations in family structure, cultural practices, beliefs, values and gender roles, as well as loss of parental agency, begin during pre-migration - and not solely as a result of flight and migration-is evidenced by the findings of this study (Williams, 2008). Additional research in the area of refugee family wellbeing, post-resettlement transitions and cross-cultural parenting supports this finding (Williams, 1990; Paulino \& Burgos-Servedio, 1997). Illuminating the ecology of the refugee parenting experience through the voices of focus group participants captures how these external conditions affect their lives. Disruption is a defining characteristic of the refugee parenting experience, which begins in pre-migration and continues in post-resettlement environs. Heightened levels of loss of autonomy and control during flight and migration might contribute to parents and carers presenting in the South Australian system of child protection.

Responding to, and seeking to eliminate, violence against children is perhaps most challenging in the context of the family, in so far as it is considered to be the most sacred of sacred terrains. However, children's rights to safety, integrity and autonomy do not stop at the door of the family home, and states' obligations to uphold these rights must prevail even within the home. Refugee parents and carers are presenting in the South Australian system of child protection (Lewig et al., 2009). The parenting practices, beliefs and values of these people might share normative spaces in their countries of origin; however, these can become decentred during resettlement in Australia (Azar \& Cote, 2002; Azar, Nix, \& Makin-Byrd, 2005). It is important that child welfare practitioners and professionals are well informed about how best to support these families through the use of culturally relevant child protection, family intervention and community development practices.

It is important to offer a conceptualisation of flight and forced migration. It is commonly accepted that forced migrants have a distinctive experience and distinctive needs (Castles, 2003; Stein, 1981). According to Turton (2003) this phenomenon is a product of wider processes of social and economic change, processes that are normally referred to as globalisation and which appear to be creating an ever increasing North-South divide in living standards, human security, and access to justice and human rights protection (Turton, 2003, p. 7-8). Consequently, the research presented here provides a window into the parenting processes associated with the beginnings of flight and forced migration and offers a way of examining and understanding these experiences on a macro level. 
Grove and Zwi (2006) describe the starting place for flight and forced migration journey as beginning at home (country of origin) and concluding with the refugees' final destination (safety and security). Further, Grove and Zwi (2006) quite aptly describe this process as often involving:

“... multiple border crossings, arduous land journeys, and protracted stays informal or informal camps. They are typically marked by ongoing fear of violence and persecution: from militants, from authorities in the host country, from those who control the camps and from other refugees. Those charged with protecting such refugees may abuse their role: United Nations peacekeepers, NGO workers, and local camp staff may exploit vulnerabilities, demanding sex. [F]or example, in exchange for access to basic supplies. The process of applying for refugee status can be long and drawn-out. The onus to demonstrate circumstances of individual persecution and the fact that only a very few applicants will be accepted for resettlement, increases anxiety and uncertainty. Some will wait for many years in 'temporary' refugee camps hoping for a visa, a few others with the resources and connections to do so attempt to make their own way to the 'safety' of a developed country" (Grove \& Zwi, 2006, p. 1932).

It is within the milieu described above that the parenting process unfolds. The environmental stressors described begin to affect the ability of the refugee family to parent (see Drachman \& Paulino, 2004; Drachman, 1992, 2005; Williams, 2010).

\section{Theoretical framework}

An ecological framework provides a method for systematically ordering the large body of data and integrating the various theoretical viewpoints. A major tenet of Ecological Theory (Bronfenbrenner \& Morris, 1998) is that the developing child is embedded in a series of nested environments that affect her or his development. Bronfenbrenner argues that there are four interrelated systems affecting the developmental processes: (a) microsystem, (b) mesosystem, (c) exosystem, and (d) macrosystem. Equally, pre-resettlement contexts (flight, migration and the refugee camp) comprise nested environments that affect and shape the refugee parenting experience.

Although accurate information on the demographics of flight, migration and refugee camps is limited, several authors (Hitchcox, 1988; Jackson, 1987; Sundhagel, 1981) elucidate the characteristics of family units in these contexts. Their findings reveal that such families possess the following characteristics: are mostly headed by females; lack one or both parents, and usually an absent father. Still less research exists that captures the impact of the refugee environment on the parenting experience (Adepoju, 1982; Calloway, 1986). Some of the environmental factors described by focus group participants as directly affecting their experience of parenting included resource allocation and scarcity within camp confines; communicable diseases; minimal healthcare services; overcrowding; and continued exposure to violence - whether domestic violence, rape or clan feuds (Waldron, 1987).

Ecological theory is often utilised extensively by child welfare practitioners throughout western industrialised countries as it offers an accessible tool for practitioners to undertake family risk assessment for children. Ecological frameworks, for some, may be too broad and bereft of class, social, and gender constructs and analysis (see Houston, 2002). However, for other child welfare practitioners, policymakers, and researchers (see Jack, 1997, 1998, 2000, 2004) the adoption of ecological theory is pivotal to the re-focusing of services towards prevention, family support, the 
alleviation of poverty, and the development of social capital; which is articulated by Houston (Houston, 2002, p. 303). The refugee ecological macrosystem offered by Williams (2008) draws upon Bronfenbrenner's notion of environmental risk factors (micro, meso, exso, and micro systems) and maps these onto the milieu of flight and forced migration to discern the parental processes of refugee families from that of western families.

\section{Analytical framework}

Qualitative data can help to build or refine conceptual models (Patton, 2002). For this research the intersections of Sidebotham's (2001) Ecological Macrosystem and Sung's (1998) Actions of Filial Piety were explored to create a new tool for transcript data analysis. The resulting analytical framework stems from a review of the parenting literature from which ecological theory was identified, which was then incorporated as a tool for understanding how families engage with systems of child protection. The analytical framework was further developed and refined through the course of the research as themes emerged from the transcript analysis. The use of this analytical method deepened understanding of the interrelationships among the components within the model proposed which reflect the stages of lived refugee parenting experiences in pre-resettlement contexts.

Three of Sidebotham's Ecological Macrosystem categories were adopted as the content areas for this research: cultural beliefs and values; the nature and role of the family; and responsibilities in parenting (Sidebotham, 2001, p. 105). Sung's (1998) Actions of Filial Piety were also instrumental and assisted with the development of actions for the Ecological Macrosystem (see Table 1). The meanings of words, phrases, sentences and paragraphs were identified within the refugee focus group transcripts, which were then made to fit into the categories of the actions (Graneheim \& Lundman, 2004). This formulation of actions for the macrosystem was aimed at enhancing understanding of the social and cultural ecology of refugee parenting, which will in turn enable practitioners to develop more explicit conceptualisations of the uniqueness of the refugee parenting experience.

The focus group provided a space in which refugee participants could describe their encounters with power shifts (around, for example, gender roles, loss of income or cultural values) based on a move from internal to external control factors (such as from personal agency to environmental factors). The method was also able to capture how participants engaged and disengaged in these seminal contexts-for example, how they coped with different levels of involvement in United Nations High Commissioner for Refugees (UNHCR) facilitated activities. 
Table 1

Actions for a Refugee Ecological Macrosystem

\begin{tabular}{|c|c|c|c|c|c|}
\hline CATEGORIES & $\begin{array}{l}\text { Cultural } \\
\text { Beliefs } \\
\text { and Values }\end{array}$ & $\begin{array}{l}\text { Nature and } \\
\text { Role } \\
\text { of Family }\end{array}$ & $\begin{array}{l}\text { Responsibilit } \\
\text { ies } \\
\text { in Parenting }\end{array}$ & $\begin{array}{l}\text { Socialization } \\
\text { Goals for } \\
\text { Children }\end{array}$ & $\begin{array}{l}\text { Preservation of } \\
\text { Parenting Norms } \\
\text { Under } \\
\text { Extraordinary } \\
\text { Conditions }\end{array}$ \\
\hline \multirow[t]{6}{*}{ ACTIONS } & $\begin{array}{l}\text { Maintaining } \\
\text { Family } \\
\text { Structure \& } \\
\text { Family } \\
\text { Continuity }\end{array}$ & $\begin{array}{l}\text { Harmonizing } \\
\text { the } \\
\text { Family }\end{array}$ & $\begin{array}{l}\text { Expressing } \\
\text { Love } \\
\text { and Affection }\end{array}$ & $\begin{array}{l}\text { Showing } \\
\text { Respect for } \\
\text { Parents/family/ } \\
\text { kin/ } \\
\text { community } \\
\text { structures }\end{array}$ & $\begin{array}{l}\text { Immediate flight, } \\
\text { Forced departure }\end{array}$ \\
\hline & $\begin{array}{l}\text { Ancestral } \\
\text { Worship }\end{array}$ & $\begin{array}{l}\text { Making } \\
\text { Sacrifices for } \\
\text { Parents }\end{array}$ & Breastfeeding & $\begin{array}{l}\text { Deference to } \\
\text { other Elders } \\
\text { and Ancestors }\end{array}$ & $\begin{array}{l}\text { Forced Separation } \\
\text { from } \\
\text { Family/Kin/Clan }\end{array}$ \\
\hline & $\begin{array}{l}\text { Observing } \\
\text { Religious } \\
\text { Teachings or } \\
\text { Animistic } \\
\text { Teachings in } \\
\text { Filial } \\
\text { Duty }\end{array}$ & $\begin{array}{l}\text { Reunification } \\
\text { of family } \\
\text { separated by } \\
\text { war, natural } \\
\text { disaster or } \\
\text { conflict }\end{array}$ & $\begin{array}{l}\text { Weaning } \\
\text { replaced by } \\
\text { other social } \\
\text { attachments } \\
\text { (e.g. siblings } \\
\text { or aunts) }\end{array}$ & $\begin{array}{l}\text { Realizing } \\
\text { parents' wishes }\end{array}$ & $\begin{array}{l}\text { Loss of Income } \\
\text { and Way of Life, } \\
\text { Loss of Identity }\end{array}$ \\
\hline & $\begin{array}{l}\text { Rituals, } \\
\text { Medicinal } \\
\text { practices or } \\
\text { childrearing } \\
\text { rituals }\end{array}$ & $\begin{array}{l}\text { Financial } \\
\text { support }\end{array}$ & $\begin{array}{l}\text { Code of } \\
\text { values, } \\
\text { courtesy, and } \\
\text { complex } \\
\text { kinship } \\
\text { behavior }\end{array}$ & $\begin{array}{l}\text { Maintaining } \\
\text { Parent \& } \\
\text { Family } \\
\text { Relationship }\end{array}$ & $\begin{array}{l}\text { Exposure to } \\
\text { Traumatic Events }\end{array}$ \\
\hline & $\begin{array}{l}\text { Observation } \\
\text { of Traditional } \\
\text { \& Religious } \\
\text { Dress Code }\end{array}$ & $\begin{array}{l}\text { Providing } \\
\text { Care to } \\
\text { Parent for } \\
\text { Loss of or } \\
\text { Disservice to } \\
\text { Family } \\
\text { Member }\end{array}$ & $\begin{array}{l}\text { Parenting is } \\
\text { shared by } \\
\text { siblings, } \\
\text { cousins, } \\
\text { wives, } \\
\text { grandparents, } \\
\text { and extended } \\
\text { kin }\end{array}$ & $\begin{array}{l}\text { Making } \\
\text { Sacrifices for } \\
\text { parents }\end{array}$ & $\begin{array}{l}\text { Risk of Losing } \\
\text { Parental Agency }\end{array}$ \\
\hline & & & Discipline & $\begin{array}{l}\text { Not giving } \\
\text { parents anxiety } \\
\text { by taking good } \\
\text { care of oneself }\end{array}$ & $\begin{array}{l}\text { Displacement/Tra } \\
\text { nsiency }\end{array}$ \\
\hline
\end{tabular}




\section{Design and method}

The research method was designed to explore and inform our understanding of why refugee parents and carers are presenting within the South Australian system of child protection. Stage I of the research involved an archival review of the literature that represents a range of issues which have resulted in notifications and substantiations (Lewig et al., 2009). Stage II involved identification of both a theoretical and an analytical framework aimed at unpacking the refugee focus group participants' narratives. Stage III included holding the focus group meetings to identify refugee parenting experiences and narratives. Stage IV involved transcript development and application of the analytical framework. Stage V included presentation of the data analysis and of the thematic results of the research. Saturation and redundancy of recurrent patterns were reached when new information was no longer identified from the transcript analysis. Completed transcripts were then examined and discussed with focus group facilitators, and amendment or correction of the data was undertaken in the case of possible data misinterpretation.

The focus group method adopted in this research presented an opportunity to engage early (within six months to one year of arrival) with a collective refugee parent or carer narrative of resettled refugees in South Australia. This approach effectively captures the nature of the unfolding preresettlement environment, including that of flight, forced migration and refugee camps, thus informing our understanding of the refugee parenting experience. The refugee groups selected were representative of the resettled refugee populations in South Australia that are presenting within the system of child protection. It is important that the method employed is reflective of culturally appropriate child protection research and practice which can identify suitable early family interventions and community development practices.

The focus group interview is a qualitative research technique primarily used to obtain data about the feelings and opinions of a small group of participants concerning a given problem, experience, service or other phenomenon (Krueger, 1998; Krueger \& Casey, 2000). In contrast, the focus group method employed in this research is exploratory, designed to consider the ecology of the refugee participants' parenting experiences in pre-resettlement contexts. Significant features of the focus group method used for this study, particularly with regard to newly resettled refugee populations in South Australia, are as follows: (a) the moderator for each group was selected because of his or her fluency in both English and the native tongue of the participants, and the moderators were also integral to the analysis of meaning undertaken before and after each session as they were either members of newly arrived refugee families themselves or community workers for the Migrant Resource Centre of South Australia (MRCSA); (b) the physical setting was deemed appropriate and readily accessible as the Migrant Resource Centre was a natural port-of-call for newly arrived refugee participants to receive essential resettlement services, counselling, referrals or other forms of assistance; (c) the psychological climate was conducive to successful group interviewing because the subjects in each group were members of the same clan, often kith and kin, and/or from the same country; (d) instrumentation involved a series of descriptive questions aimed at identifying the ecology of participants' parenting experiences in pre-resettlement contexts; and (e) for data analysis a framework was developed to analyse how the participants' narratives reflected the ecology of the refugee parenting experience (see Table 1). 


\section{Sample and procedures}

Sample \& Recruitment Techniques

Approval for the research project was obtained from the University of South Australia Human Research and Ethics Committee and the South Australian Families and Communities Research Ethics Committee. In research conducted by Lewig et al. (2009); the precursor to the research presented here; data collection involved survey, interviews, and focus group methods with statutory child protection practitioners and refugee community members.

The Migrant Resource Centre of South (MRCSA) is an independent, non-government peak settlement agency responsible for the settlement and participation of migrants and refugee entrants across all of South Australia. The MRCSA under the IHSS has primary responsibility for settling humanitarian entrants in the Adelaide metropolitan region upon arrival. These comprise new arrivals from a diversity of cultural and religious backgrounds arriving with their family members or joining family members already settled in South Australia. The MRCSA was established in 1979.

The Centre has worked with different waves of migrant and refugee settlement groups in order to assist them to adjust to their new homeland, to become self reliant, and to develop linkages with the broader community and with their local ethnic communities. In addition to its service delivery role and functions, the MRCSA advocates on behalf of its client groups and represents their interests to all levels of government. To that end, it actively contributes to mainstream public policy and service planning which impacts on the health and wellbeing, equitable access to services and social inclusion of Australians from culturally and linguistically diverse backgrounds.

According to the Australian Department of Immigration and Citizenship (DIAC) (2008) more than 660, 000 refugees have resettled in Australia. In the mid- to late 1990s until 2003, the majority of humanitarian entrants have come from Africa (i.e., Sudan), the former Yugoslavia (today known as Bosnia and Herzegovina, Croatia, Kosovo, Macedonia, Montenegro, Serbia), the Middle East, and Southeast Asia (DIAC, 2008). As the MRCSA is the peak body for the resettlement of refugees in the state of South Australia it was approached to recruit parent participants for this study from the aforementioned refugee populations. Based on Lewig et al (2009) research these groups are presenting in child protection systems (with exception of families from Afghanistan).

The staff of the MRCSA selected the focus group participants to represent a cross-section of refugee parents and carers of children aged from 1 to 12 years). All participants were newly arrived, having spent less than a year in South Australia, and either had a personal or a once removed experience (for example, knew someone who had been in contact with Families, SA) with the South Australian system of child protection. The ages represented within each group ranged from 21 to 70 years old. The focus groups were flexibly designed to accommodate participants' limited English language skills, and most (other than the men's group) were undertaking English language training courses and/or had family commitments during the day - therefore attendance could vary between 8 and 15 participants at any given session (see Table 2 below).

\section{Procedures}

The sample consisted of three focus groups ranging in size from 8 to 15 participants per session (with a maximum total of $\mathrm{n}=35$ ). Participation was voluntary and based on a revolving door policy, such that participants were free to attend or leave at any time. A Sudanese women's group (Dinka 
and Nuer), an African men's group (Congo, Ethiopia, Liberia, Somalia and the Sudan), and an Afghani and Iraqi women's group were formed. This sample provided an opportunity to better understand how refugee groups composed of individuals from different cultural backgrounds experience parenting.

The participants were homogeneous in their shared status as refugees and consequent experiences of 'otherness', and in some cases in their countries of origin. However, they were heterogeneous in their clan identifications; religious affiliations; gender; and experiences of flight, migration and refugee camps. Homogeneity is not a strict requirement for exploratory focus group research; indeed, heterogeneity was achieved across the focus group sample in this research, which provided a diverse and rich source of information. Separate sessions were conducted for each group and were divided along gender lines. The analytical framework and coding processes were aimed at eliciting the refugee participants' differential pre-resettlement experiences in order to identify the overarching meta-themes.

\section{Informed consent}

Obtaining informed consent occurred in stages. Stage I involved four informed consent sessions for varying levels of the MRCSA management team, staff, administrators, and family workers preselected by the MRCSA who served as focus group facilitators and translators. In Stage II, two introductory informed consent sessions were conducted per focus group with one upper management MRCSA staff member present for each. Participant Information Sheets were translated for both women's groups, but not for the men as they were fluent in English. Oral consent was obtained in cases of participant illiteracy by both the facilitator and the individual as participants in this category had minimal writing skills.

\section{Focus Groups \& Facilitators}

Focus group facilitators were selected by the Migrant Resource Centre of South Australia. To preserve the anonymity of facilitators and parent participants' additional detailed information was not collected or presented. Focus group questions utilised during sessions were semi-structured and facilitators were given an opportunity to review the questions, revise, or query any of the content for clarification purposes. Each facilitator represented the culture and country of origin of participants. The researcher met with facilitators as many times as required prior to the start of the focus group sessions. The facilitators completed consent forms.

The facilitators selected participants whom they deemed would benefit and were suitable for the research. An information session was provided for prospective participants. During these sessions attendees were asked to indicate their interest in participating in the focus group research. The facilitators were instrumental for the conduct, translation, and flow of focus group discussion. The researcher was present at each focus group session (see Williams, 2008). At the close of each focus group the researcher and facilitator conducted post-session consultations to reflect on observations made during each focus group.

Each session was conducted by preparing the room allocated by the MRCSA to conduct the research. Food, a chat, coffee, tea, and blessings were offered prior to the commencement of each session. Each session was conducted in a similar fashion-largely unstructured. The focus group 
session ended because resources did not permit continuation as well as the research deadline was reached.

Transcripts were derived from 15 3.5-hour focus group sessions. Facilitators assisted with transcript coding. The focus group sessions were audiotaped and notes were also taken by the researcher and the facilitator. Sessions ran longer that anticipated due to interpretation At the conclusion of the research follow-up unstructured interviews (unrecorded) and coding sessions occurred with facilitators both in-person and via telephone.

Table 2: Focus Group Matrix

\begin{tabular}{|c|c|c|c|c|c|c|}
\hline $\begin{array}{l}\text { Focus Group } \\
\text { Composition }\end{array}$ & $\begin{array}{l}\text { Number } \\
\text { and } \\
\text { Length of } \\
\text { Sessions }\end{array}$ & $\begin{array}{l}\text { Number of } \\
\text { Participants }\end{array}$ & $\begin{array}{l}\text { Refugee } \\
\text { Camp }\end{array}$ & $\begin{array}{l}\text { Period in } \\
\text { Australia }\end{array}$ & $\begin{array}{l}\text { Family } \\
\text { Composition }\end{array}$ & Comments \\
\hline \multicolumn{7}{|l|}{ Sudanese Women } \\
\hline $\begin{array}{l}\text { Dinka } \\
\text { Nuer }\end{array}$ & $6 @ 3.5 \mathrm{hrs}$ & $6-10$ & $\begin{array}{l}\text { Egypt } \\
\text { Kenya }\end{array}$ & $\begin{array}{l}<6 \\
\text { months } \\
\text { to }<1 \mathrm{yr}\end{array}$ & $\begin{array}{l}\text { Married } \\
\text { Single } \\
>2 \text { children } \\
>2 \text { adolescents }\end{array}$ & $\begin{array}{l}2 \text { Elder } \\
\text { Sudanese } \\
\text { women } \\
\text { (great/grandp } \\
\text { arents) }\end{array}$ \\
\hline $\begin{array}{l}\text { African Men } \\
\text { Burundi, Congo } \\
\text { Ethiopia, Liberia } \\
\text { Sierra León, Sudan }\end{array}$ & $5 @ 3.5 \mathrm{hrs}$ & $8-10$ & $\begin{array}{l}\text { Egypt } \\
\text { Kenya }\end{array}$ & $\begin{array}{l}<6 \\
\text { months } \\
\text { to }<1 \mathrm{yr}\end{array}$ & $\begin{array}{l}\text { Married } \\
\text { Single } \\
>2 \text { children } \\
>2 \text { adolescents }\end{array}$ & $\begin{array}{l}\text { Ethiopian } \\
\text { Elder } \\
>50 y r s \text { in age } \\
\text { participant } \\
\text { lived in } \\
\text { Australia >10 } \\
\text { yrs }\end{array}$ \\
\hline $\begin{array}{l}\text { Arab Women } \\
\text { Afghanistan } \\
\text { Iraq }\end{array}$ & 5 @ 3.5hrs & $8-15$ & Iran & $\begin{array}{l}<6 \\
\text { months } \\
\text { to }<1 \mathrm{yr}\end{array}$ & $\begin{array}{l}\text { Married } \\
\text { Single } \\
>2 \text { children } \\
>2 \text { adolescents }\end{array}$ & $\begin{array}{l}>5 \text { Afghani } \\
\text { women single } \\
\text { mothers }\end{array}$ \\
\hline $\begin{array}{l}\text { Personal Interviews } \\
\text { w/ SA } \\
\text { Refugee Family } \\
\text { Workers } \\
\text { Congo (Male) } \\
\text { Ethiopia (Male) } \\
\text { Iraq (Female) } \\
\text { Liberia (Female) } \\
\text { Sudan (Male) }\end{array}$ & $4 @ 2.5 \mathrm{hrs}$ & $\begin{array}{l}\text { 2-w/female } \\
3-w / \text { male }\end{array}$ & $\begin{array}{l}\text { Ghana } \\
\text { Kenya }\end{array}$ & $>1 \mathrm{yr}$ & $\begin{array}{l}\text { Married } \\
\text { Single } \\
>2 \text { children } \\
>2 \text { adolescents } \\
1 \text { grandparent }\end{array}$ & $\begin{array}{l}\text { Follow-up by } \\
\text { telephone } \\
\text { and/or in } \\
\text { person was } \\
\text { required }\end{array}$ \\
\hline Total & $20 @ 13 \mathrm{hrs}$ & 62 & 4 & $>1 \mathrm{yr}$ & $>3$ & $\begin{array}{l}\text { Each group } \\
\text { desired more } \\
\text { sessions }\end{array}$ \\
\hline
\end{tabular}


The collective participants' narrative developed exponentially, particularly as trust was established. The focus group questions utilised in the study with refugee parents and carers were semistructured with the aim of creating a discussion where experiences and stories could be shared between participants. Questions were designed to explore pre-resettlement parenting experiences within the milieu of flight and forced migration. In the early stages and development of Lewig et al. (2009) research questions emerged regarding capturing refugee parenting experiences early. Although focus group questions were reviewed by my Supervisors, due to the lengthy process often associated with interpretation and the evolving nature of discussion groups (as conducted by facilitators), all of the questions presented were not utilised in their strictest form. All of the questions were not asked during all of the groups (as focus groups discussions were only minimally structured)

The following questions are exemplary of those used to generate the initial discussion for each group, after which point the sessions continually evolved in terms of content and theme (such that each session began with a summary of the previous session): (a) Can you describe what the word 'family' means in your culture? (b) What is the role of the family and who are its members? (c) What is the role of the mother? (d) What is the role of the father? (e) Who is responsible for raising the children? (f) Can you describe the most important cultural traditions for the family? (g) How does your culture and family address child disobedience? (h) What does child protection mean? (i) How did your parenting experience change once you were forced to leave your home? (j) What has changed for you in Australia? The responses to these questions were analysed using qualitative content data analysis (Fowler, 1995).

The use of focus groups as a qualitative approach to working with refugee participants provided a familiar environment for them-in terms of gender, language, culture and the building of support networks. According to Watters (1998a, 1998b; 1999; 2001) a recommended mechanism for consultation with refugee groups is the focus group method. These have proven to be useful forums for addressing issues relating to healthcare provision (Watters, 2001, p. 1714). Watters (2001) and others (see also My \& Cunninghame, 1996) argue that the focus group method among refugee communities may be a useful means of prioritising proposals for the setting up of specific services relating to the health, wellbeing and social care needs of refugees (Watters, 2001, p. 1714) The focus group method was utilised in the research presented here because it provided a sense of safety in numbers. According to some authors (Harrell-Bond et al., 1992; Kreitzer, 2002; Ochocka \& Janzen, 2008; Oke, 2008) such a format gives a voice to disempowered groups or those in fear of negative feedback. After conducting extensive research into identifying the most appropriate methodology to engage refugee parents; the results suggest that, if handled skillfully, this technique offers refugee communities opportunities to be active participants in identifying priorities and delivering services (see also Pourgourides et al., 1996).

Utilising focus groups and subsequent personal interviews facilitated understanding of both the explicit and implicit aspects of the refugee parenting experience in pre-resettlement contexts. Understanding refugees' cultural beliefs and values regarding the nature and role of the family, responsibilities in parenting, and culturally based socialisation goals for children will assist in the development of culturally appropriate child protection policy and practice in post-resettlement family interventions. Focus group methodology is ideal for organising small, informal discussions 
among individuals on select topics and eliciting participants' own meanings, concepts and language, and is particularly relevant for newly arrived, resettled refugees whose first language is not that of the dominant culture (in this case, English). In this research it was necessary to have each focus group facilitated by the respective community's family worker employed by the MRCSA, who also translated and moderated each session.

Although the focus group method is suitable for the aims of this study, it is limited by the inability to draw inferences about larger refugee populations or to allow statistical testing or interval estimations, which require quantitative data. Several key challenges emerged during the focus group sessions, including: (a) time lost in the translation of native languages into English; (b) a restriction on the number of focus groups possible because of the cost of providing lunch and morning and afternoon teas for participants; (c) constraints around scheduling and access to the space provided by the MRCSA; and (d) most importantly, because refugee participants were new arrivals they were engaged in receiving resettlement services (such as English language education) during the day, which hindered their ability to participate. The focus group method cannot resolve the many problems involved in cross-cultural parenting, child protection and family wellbeing research. However, its methodological strengths suggest that child protection practitioners and policymakers could benefit from greater familiarity with the particular ecology of refugee parenting in pre-resettlement contexts. In addition, although this method has been under-utilised in the areas of health and psychology research in the past, it is likely to receive greater attention in the future because of its versatility and ability to inform future research, resettlement planning, and the development of services that are culturally appropriate and relevant.

\section{Reliability \& Validity}

A great deal of attention is applied to reliability and validity in all research methods. A challenge to rigor in qualitative inquiry interestingly parallels the burgeoning development of statistical packages and computing systems in currently available quantitative research. Some authors (Guba \& Lincoln, 1994; Leininger, 1994; Morse et al., 2002) suggest adopting new criteria for determining reliability and validity.

To obtain reliability and validity, the research process presented here engaged in the following strategies to attain trustworthiness such as peer debriefing, prolonged engagement (i.e., 3 hour focus group sessions) and persistent observation (i.e., audiotaped sessions). Also important to the research presented here were characteristics of the facilitators, who were to be responsive and adaptable to changing circumstances, holistic (i.e., MRCSA family workers), having sensitivity, ability for clarification and summarization (see also Guba \& Lincoln, 1994).

Maintenance of particular standards were present from the beginning of the research (as represented by ethics approval) through to the development of a comprehensive approach to evaluating the research as a whole; which was primarily reliant on procedures or checks developed by the researcher for facilitators to be used following completion of the research. Strategies for ensuring rigor were embedded into the qualitative research. When used appropriately, these strategies force the researcher to correct both the direction of the analysis and the development of the study as necessary (i.e., Oxford Certificate in Forced Migration), thus ensuring inter-rater reliability and validity of the completed project. 
Qualitative research is iterative rather than linear, so that a good qualitative researcher moves back and forth between design and implementation to ensure congruence among question formulation, literature, recruitment, data collection strategies, and analysis. Data are systematically checked-in this case focus group transcription allows for maintenance of focus, and the fit of participants, data and the conceptual framework of analysis and interpretation are monitored and confirmed throughout. Verification strategies helped the researcher to identify when to continue, stop or modify the research process in order to achieve reliability and validity and consequently ensure rigor.

\section{Generalizability}

The refugee parent participants and experiences are not necessarily reflective of all pre- or postresettlement experiences. There were time and resource limitations to the study. The research aimed to identify participants from those countries of origin presented within the Lewig et al (2009) sample. There are limitations in undertaking cross-cultural qualitative research (i.e., researcher represents a different cultural background). However, simultaneously the researcher was granted greater access and trust because she is a migrant to South Australia, a parent, and both her ancestral background and religious upbringing presented a shared foundational scaffold for engagement.

\section{Results and analysis}

Coding: Actions for an ecological macrosystem

Transcript coding in this research occurred in steps. The first step in the coding process required locating texts within the focus group transcripts that could be placed within the actions to become meaning units. The second step involved condensing these excerpts (that is, meaning units) into condensed meaning units. The third step in the content analysis procedure involved identifying the intersections of condensed meaning units and categorising these into sub-themes and the resulting dominant themes.

There is a dearth of research into single parent refugees, refugee caregivers and specifically the ecology of parenting within the environment of flight and forced migration. A descriptive taxonomy of categories and concrete actions was developed in this study to describe the ecological environment of parenting within pre-resettlement contexts. Transcripts were analysed using the content analysis method. Categories and actions were devised to identify meaning units and condensed meaning units, which were subsequently translated into sub-themes and concluding themes, with the aim of developing a comprehensive understanding of the refugee parenting experience.

A similar style of qualitative research was conducted by Hsueh, Hu \& Clarke-Ekong (2008) in their exploration of acculturation in filial practices among 21 Chinese immigrants, who referred to the research process as thematic content analysis. Through a process of open coding and categorising, these authors identified key phrases on which to base their formulation of codes and major categories. Major categories were grouped and further analysed to determine subcategories to reflect situational perspectives on acculturation in relation to filial values. These procedures were adapted and applied to the present context of refugee-related data.

Similar to Wilkinson's (1998) review of published reports of focus group studies, this research has enabled improved access to participants' own language and concepts around their experiences, 
better understanding of participants' agendas, and the production of more detailed accounts by utilising meaning units for coding. The categories and actions outlined below allowed for fluid transcript analysis, as the breadth of each transcript ranged from 30 to 60 pages. The transcript analysis process involved movement in, among and between the transcripts, entailing coding, analysis and conceptualisation. This process enabled the construction of distinct meanings for words, phrases, sentences and paragraphs (Williams, 2008, p. 12).

The overarching categories for the Ecological Macrosystem are: (a) Cultural Beliefs and Values; (b) Nature and Role of Family; (c) Responsibilities in Parenting; (d) Socialisation Goals for Children; and (e) Preservation of Parenting Norms under Extraordinary Conditions. These categories represent fundamental cultural beliefs and values associated with traditional societies. Woven into the macrosystem categories are action codifiers for the particular experiences of war, the disruption of lives, pre-flight, flight and migration, and refugee camps. These are reflected in daily life and behavioural patterns; the (re)organisation of society; and the attitudes and beliefs that underlie these cultural manifestations. It is important that the ecology of the refugee parenting experience not be viewed as static, but rather as comprised of layered transparent elements of experience often appearing simultaneously, at times partially obscuring other elements, and occurring as a metadynamic, consequently shaping and moulding child development.

Examples of actions are: (a) Showing Respect for Community Structures; (b) Loss of Way of Life; (c) Code of Values; (d) Harmonising the Family; (e) Shared Parenting; and (f) Showing Respect for Parents. This list is not intended to be exhaustive, but to provide examples that show how different factors can fit within an ecological model. It is important to note that some factors might operate on more than one level. Investigating the ecology of the refugee parenting experience involves the study of the progressive, reciprocal interaction between an active, developing human being and the changing properties of the immediate settings in which that person lives, and this process is affected by relations between these settings and the larger contexts (such as war, flight and migration) in which the settings are embedded. 


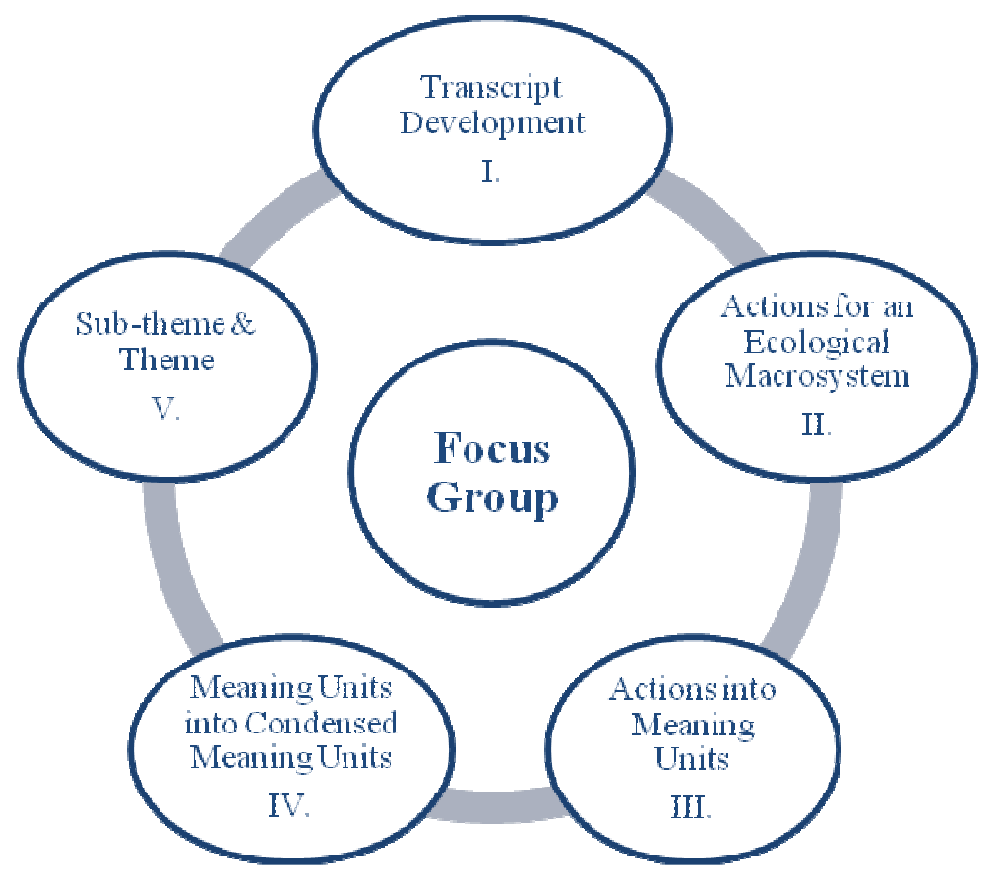

Figure 1: Transcript Analysis and Process

The concept of 'theme' can have multiple interpretations. Establishing themes is a way to link underlying meanings across focus group transcript analysis into categories, according to Polit and Hungler (1999). A theme is a recurring representation of meaning developed within categories or cutting across categories. Authors such as Baxter (1991) define themes as threads of meaning that recur across domains. Other authors argue that a theme describes an aspect of the structure of experience (van Manen, 1990). A theme answers the question 'How?' A theme can be viewed as a thread of an underlying meaning, revealed through condensed meaning units, codes or categories, at an interpretative level (Downe-Wamboldt, 1992; Krippendorff, 1980). For the purposes of the research presented here themes are comprised of sub-themes. The motive for dissecting and (re)presenting the participants' collective narrative is to illustrate the existence of multiple realities and the diversity of these realities, and to allow the reader entry into these localised spaces.

The questions utilised were designed to elicit descriptions of the parenting experience and the preresettlement environment in which parenting occurred. As the focus group discussions evolved and trust was established, the discussions transcended these subject areas and participants desired to send a message-not solely to Families, SA or to Australia as a whole-but a meta-message. This message, signifying 'I am' and 'my history', is important in that it allows Australians to understand the palette of refugees' lives, cultures and traditions. The focus group provided a space for the collective sharing and expression of what refugees hold most dear-their memories of the past, culture, tradition, family, and maintaining a state of normality. This coexistence of many selves in many contexts inherent to the refugee experience in general and refugee parenting in particular comes to light by using the focus group medium. Participant-based research allows for the location of voice and agency. 
In most refugee and displacement contexts, the roles and responsibilities of men and women change because of the impact conflict and/or displacement has on family and community structures. For example, women might become the breadwinners and men might assume responsibility for childcare (UNHCR, 2006a). There is a need for Australian resettlement agencies to engage in assessment and analysis of refugee situations from a gender-based perspective to foster successful gender-specific integration. Australian resettlement agencies must carefully analyse the socially assigned roles of women and girls, men and boys, and elders in these communities. According to the UNHCR (2006a, 2006b), in most situations women are the primary caregivers for children, the sick and the elderly. The power relations between women and men, and how these impact on women's participation in decision-making and their access to and control of resources and physical security, need to be better understood. When violations of women's and girls' rights, or inequalities between women and men, are identified in any operation, UNHCR programs should seek to address these through sustainable action-oriented, community-based initiatives.

Transcript development and analysis proceeded with facilitators after each session to decontextualise session notes and were available for follow-up meetings and telephone queries as needed. Although the idea of saturation is helpful at the conceptual level, it provides little practical guidance for estimating sample sizes prior to data collection, which is necessary for conducting quality research. Data collected in this research were used to systematically document the degree of data saturation and variability over the course of thematic analysis-to generate sub-themes and meta-themes (see Figure 2 below). The analytical framework and coding processes operationalised saturation.

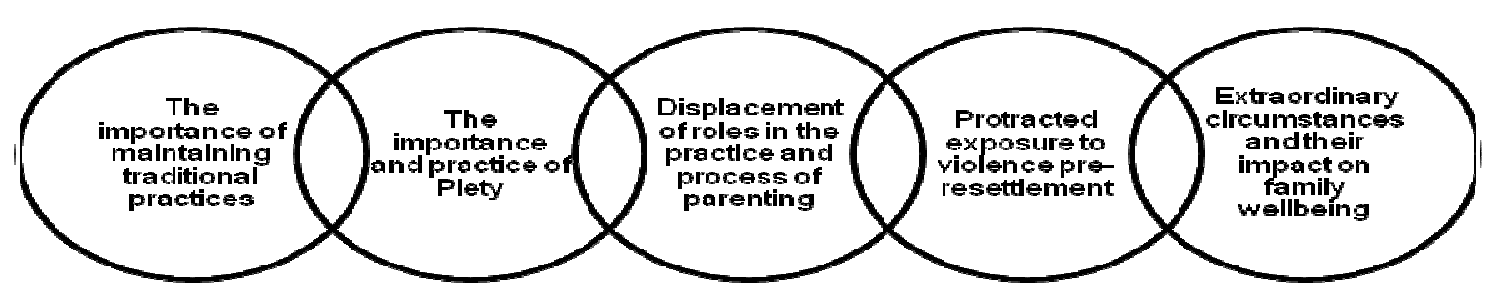

Figure 2: Focus Group Meta-Themes

\section{Research utility and messages from the field}

An ecological approach to working with families and children in the child welfare system is defined as an approach that understands a child as located within the context of his or her family (for example, in relation to parents, caregivers and the wider family) and of the community and culture in which he or she is developing (Department of Health, 1999). This approach is also commonly associated with the domain of child welfare and social work, and with determining child wellbeing 
on the basis of the social ecology of parents and children. Stemming from human ecology, social ecology examines the ways in which people and their environments shape and influence one another through a process of interaction and mutual reinforcement (Garbarino, 1981).

Ambert's (1994) work illustrates the effect socioeconomic change and upheaval has on the experience of parenting, which in future in the context of flight and migration might become increasingly problematic throughout the world. If, as Ambert (1994) asserts, childhood and parenting are viewed as social constructs that evolve within socio-historical environs then it is equally true that they are impacted by international developments which can be presumed to affect not only the ecology of refugee parenting, roles, beliefs, practices and norms but also research paradigms (Barnett, 2008; Magnuson \& Duncan, 2002; Teti \& Candelaria, 2002).

Researchers who have moved beyond classical interpretations of migration offer both historical and sociological analyses (Yans-McLaughlin, 1990; Tilly, 1990) such as those driven by ethno-culturally based research on groups within the United States (Asians, African-Americans and Latinos). Such ethno-cultural research has been conducted in refugee camps to a lesser extent. However, service provisions (such as healthcare) within these settings have focused on sexual and gender-based violence, harmful practices and domestic violence (Bonar \& Roberts, 2006; Menjivar \& Salcido, 2002). Yet research into, and developments in the provision of, ethno-culturally based services within camp settings in post-resettlement contexts are increasing (Ajdukovic, 1996; Keyes, 2000; Pine \& Drachman, 2005), particularly in relation to adaptation and acculturation (Goodkind \& Foster-Fishman, 2002; Masten \& Reed, 2002). There is also a heightened interest in research regarding the consequences for asylum seekers of long-term residence within detention centres (Fazel, Wheeler, \& Danesh, 2005). Azar and Cote's (2002) examination of the literature within psychology concludes that current research emphasises measuring socialisation goals that are individually driven as opposed to group-oriented or communal goals, such as independence and individuality versus acts of piety.

\section{Discussion}

The findings drawn from the focus group research presented here are consistent with the accounts provided by other international authors (Ochocka \& Janzen, 2008) of the challenges faced by newly arrived immigrants. However, the ecological complexity of issues confronting refugee parents and carers in the context of pre-resettlement has not been thoroughly explored. Ochocka and Janzen (2008) discuss the particular parenting challenges faced by immigrants in Canada, which correlate with the results of Williams's (2008) research. For example, these authors concluded that participants in their research experienced a loss of the social structure that supported their parenting values, beliefs, norms and strategies for coping. Ochocka and Janzen have also highlighted the limitations of existing parenting models (such as those of Baumrind, 1971; Levine, 1980) in seeking to uncover and conceptualise the process and outcomes of parenting for newly arrived immigrant families.

Weine et al. (2005) attest to a lack of theory or empirical research concerning refugee families' and their mental health that might guide practice, policy and research. These authors state that the limited volume of family therapy literature on refugee families consists primarily of clinical reports and theories that tend to focus on problematic interpersonal aspects of the refugee experience such as family disruption, traumatic memories, or gender-based and intergenerational conflict (Weine et 
al., 2005, p. 558). As noted by these authors, refugee families are distinct from general immigrant and migrant populations as a result of their experiences associated with pre-flight, flight and forced migration (see also Balgopal, 2000; Barnett, 2008). Weine et al. (2005) have incorporated multiplefamily groups in their research into Bosnian refugee families as part of an approach to intervention they have found to be effective which is focused on family strengths and resilience and is aimed at assisting families to cope with adversity. However, as has been argued by these authors, neither the immigrant nor the refugee literature presents empirical research on family-focused mental health interventions or outreach with refugee families-hence the need for the research presented here.

Parent management training is another widely used intervention aimed at improving parenting skills (Forehand \& Kotchick, 2002; Kotchick \& Forehand, 2002; Moran \& Ghate, 2005). Research models and ecological frameworks that seek to understand child abuse and neglect often do not consider the refugee parent or carer's own resources (such as social and kinship networks) (Cochran \& Niego, 2002; Colic-Peisker \& Tilbury, 2003), ethno-cultural background and demographic history (Coll \& Pachter, 2002; Collins, 1996), or the unique characteristics of flight and migration. Various early intervention parent training programs exist which are widely used by child welfare services to improve the parenting practices of families referred for child maltreatment. However, a parent-centred education support service that is specific to the needs of refugees is lacking. Despite variations in composition and delivery, the elements that determine effective parent training programs have rarely been examined. As there are continuing debates concerning the aetiology of child abuse and neglect it is difficult to mainstream evaluation efforts that are culturally relevant and an appropriate fit for refugee parents and carers.

Many authors (Lim \& Lim, 2004; Roopnarine et al., 2006) concur that an understanding of culture is vital to gaining an understanding of parenting. Immigrant parenting styles are not unchanging or homogeneous, but rather develop over time, and this is equally true in the context of pre-flight, flight and forced migration. Indeed, Ochocka and Janzen (2008) argue that there are a wide range of ecological factors which need to be considered. They stress the importance of developing frameworks that explore the multiplicity of factors that impact on parenting practice in the context of 'ever changing ecologies and new situations' (Ochoka \& Janzen, 2008, p. 88). The focus group method and the theoretical and analytical framework employed in this research are designed to contribute to previous investigative efforts around the changing ecologies of refugee parenting in pre-resettlement contexts.

\section{Conclusion}

In conclusion, parenting ability, competency and support are increasingly becoming a concern for child welfare practitioners, educators and policymakers, as witnessed by a growth in parenting research and interventions for these populations. Cultural knowledge informs such professionals about the unique refugee parenting context when working with these families and their children. The experiences of focus group participants in this study of flight and forced migration have shaped their childrearing practices. Understanding the ecology of these spaces plays a significant role in increasing communication between the outsider (such as the counsellor) and the client (the refugee), and facilitates consideration of the client's culture of origin. Recognition of how culture informs parents' socialisation goals for their children will impact child protection practice and service delivery. 
The guiding research question for Lewig et al (2009) is identified as why refugee parents are presenting to South Australian child protective services. While focus group participants in the research presented here did not have direct contact with South Australian systems of child protection, many did however, have a once or twice removed (i.e., a community member, a child's friend from school, and/or neighbour) knowledge of persons in contact with child welfare. The research presented here explored what occurs to the refugee parenting process-as affected by the milieu of flight and forced migration (i.e., pre-resettlement contexts); to inform South Australian child protection practitioners, policy, and research to assist refugee parents to meet the challenges associated with post-resettlement (i.e., parenting in a new culture).

As the focus groups transcription unfolded early themes identified (see Williams, 2008) pointed toward the need for child welfare early interventions (i.e., parenting education) within the context of refugee camps on behalf of both the UNHCR and humanitarian service providers; which led to broadening the researchers lens to include participating and acquiring a Certificate from the University of Oxford, International Summer School of Forced Migration, Refugee Studies Centre, Department of International Development.

Refugee parents and carers newly arrived in South Australia, according to focus group participants; do not possess prior knowledge of Australian parenting norms, expectations or systems of child protection. This qualitative research study provided an opportunity for refugee participants to reflect on their parenting experiences during pre-flight, flight and forced migration with others who share a common ethno-cultural or geographic background. The focus group discussions, transcript analysis, and follow-up interviews deepened understanding of refugee parenting experiences, taking into account both culture and context. The community groups involved expressed a desire to receive feedback regarding the research results and asked whether similar activities might become common practice in future.

The model offered here is proposed as a useful framework to enable researchers, practitioners and Australian resettlement agencies to better understand refugee parenting practices and more importantly to consider the broader ecological environment of pre-flight, flight and forced migration which affects these parenting processes. The findings of this study provide evidence to support the use of the focus group method as an approach to engage newly arrived refugee parents and carers, in order to strengthen refugee resettlement transitions to South Australia. Continued investigation into the ecology of refugee parenting in pre-resettlement contexts is needed.

\section{References}

Adepoju, A. (1982). The dimension of the refugee problem in Africa. African Affairs, 81, 21-35.

Ajdukovic, M. (1996). Mothers' perception of their relationship with their children during displacement: A six-month follow-up. Child Abuse Review, 5(1), 34-49.

Ambert, A.-M. (1994). An international perspective on parenting: Social change and social constructs. Journal of Marriage and the Family, 56(3), 529-543. 
Azar, S. T., \& Cote, L. R. (2002). Sociocultural issues in the evaluation of the needs of children in custody decision making: What do our current frameworks for evaluating parenting practices have to offer? International Journal of Law and Psychiatry, 25(3), 193-217.

Azar, S. T., Nix, R. L., \& Makin-Byrd, K. N. (2005). Parenting schemas and the process of change. Journal of Marital and Family Therapy, 31(1), 45-58.

Balgopal, P. R. (2000). Social work practice with immigrants and refugees. New York: Columbia University Press.

Barnett, M. A. (2008). Economic disadvantage in complex family systems: Expansion of family stress models. Clinical Child and Family Psychology Review 11(3), 145-161.

Baumrind, D. (1971). Current patterns of parental authority. Developmental Psychology Monographs, 1, 1-103.

Baxter, L. A. (1991). Content analysis. In B. M. Montgomery, \& Duck, S. (Ed.), Studying interpersonal interaction (pp. 239-254). London: Guilford Press.

Bonar, M., \& Roberts, D. (2006). A review of the literature relating to family and domestic violence in culturally and linguistically diverse communities in Australia. Family and Domestic Violence Unit (Ed.). Western Australia: Department for Community Development.

Bronfenbrenner, U., \& Morris, P. A. (1998). The ecology of developmental processes. In W. Damon, \& Lerner, R.M. (Ed.), Handbook of psychology (Vol. 1, pp. 993-1028). New York: Wiley.

Calloway, H. (1986). Refugee Women: Specific Requirements and Untapped Resources. In G. Altaf (Ed.), Third World Affairs (pp. 320-325). London: Third World Affairs Foundation.

Castles, S. (2003). Towards a sociology of forced migration and social transformation. Sociology, $37(1), 13-34$.

Cochran, M., \& Niego, S. (2002). Parenting social networks. In M. Bornstein (Ed.), Handbook of parenting (Vol. 4, pp. 123-149). Mahwah, New Jersey: Lawrence Erlbaum Associates.

Colic-Peisker, V., \& Tilbury, F. (2003). The influence of support services and refugees' own resources on resettlement style. International Migration, 41(5), 62-89.

Coll, C. G., \& Pachter, L. M. (2002). Ethnic and minority parenting. In B. Webber (Ed.), Handbook of parenting (Vol. 4, pp. 21-46). Mahwah, New Jersey: Lawrence Erlbaum Associates.

Collins, P. (1996). Shifting the center: Race, class and feminist theorizing about motherhood. In E. N. Glenn, Chang, G., \& Forcey, L. R. (Ed.), Mothering ideology, experience, and agency (pp. 45-65). New York: Routledge. 
Department of Health. (1999). Framework for the assessment of children in need and their families. London: Department of Health.

Department of Immigration and Citizenship. (2007). South Australia Settlement Trends and Needs of New Arrivals 2007. Belconnen, ACT: Department of Immigration and Citizenship.

Department of Immigration and Citizenship. (2008). Refugees EHumanitarian, Migrating as a Refugee. Canberra: Australia: DIAC. Retrieved June 9, 2008 from http://www.immi.gov.au/refugee/migrating/index.htm.

Downe-Wamboldt, B. (1992). Content analysis: Method, applications, and issues. Health Care for Women International, 13(3), 313-321.

Drachman, D. \& Paulino, A. (2004). Immigrants and social work: Thinking beyond the borders of the United States. Journal of Immigrant and Refugee Services, 2(1/2), 1-9.

Drachman, D. (1992). A stage of migration framework for services to immigrant populations. Social Work, 39, 188-197.

Drachman, D. (2005). The migration experience: Understanding immigrants and refugees. In R. Link, \& L. Healy (Eds.), Teaching international content: Curriculum resources for social work education. Alexandria, Virginia: Council on Social Work Education.

Fazel, M., Wheeler, J., \& Danesh, J. (2005). Prevalence of serious mental disorder in 7000 refugee resettled in western countries: A systematic review. Lancet, 365, 1309-1314.

Forehand, R., \& Kotchik, B. A. (2002). Behavioral parent training: Current challenges and potential solutions. Journal of Child and Family Studies, 11, 377-384.

Fowler, F. J. (1995). Improving survey questions: design and evaluation. Thousand Oaks: Sage.

Garbarino, J. (1981). An ecological approach to child maltreatment. In L. H. Pelton (Ed.), The social context of child abuse and neglect (pp. 228-261). New York: Human Sciences Press.

Goodkind, J. R., \& Foster-Fishman, P. G. (2002). Integrating diversity and fostering interdependence: Ecological lessons learned about refugee participation in multiethnic communities. Journal of Community Psychology, 30(4), 389-409.

Graneheim, U., \& Lundman, B. (2004). Qualitative content analysis in nursing research: Concepts, procedures, and measures to achieve trustworthiness. Nurse Education Today, 24, 105-112.

Grove, N.J., \& Zwi, A.B. (2006). Our health and theirs: Forced migration, othering, and public health. Social Science \& Medicine, 62, 1931-1942.

Guba, E.G., \& Lincoln, Y.S. (1994). Competing Paradigms in Qualitative Research. Handbook of qualitative research (p. 105-117). New York: Sage. 
Harell-Bond, B., Voutira, E., \& Leopold, M. (1992). Counting the refugees: Gifts, givers, patrons, and clients. Journal of Refugee Studies, 5, 205 -225.

Hitchcox, L. (1988). Vietnamese Refugees in Transit: Process and Change. University of Oxford, Oxford.

Houston, S. (2002). Rethinking a systematic approach to child welfare: a critical response to the framework for the assessment of children in need and their families. European Journal of Social Work, 5(3), 301-312.

Hsueh, K.-H., Hu, J., \& Clarke-Ekong, S. (2008). Acculturation in filial practices among U.S. Chinese caregivers. Qualitative Health Research, 18(6), 775-785.

Indra, D. (1999). Engendering forced migration theory and practice (Vol. 6). New York: Berghahn Books.

Jack, G. (1997). Discourses of child protection and child welfare. British Journal of Social Work, 27, 659-678.

Jack, G. (1998). The social ecology of parents and children: Implications for the development of child welfare services in the UK. International Journal of Child and Family Welfare, 98(1), 78-88.

Jack, G. (2000). Ecological influences on parenting and child development. The British Journal of Social Work, 30(6), 703-720.

Jack, G. (2004). Child protection at the community level. Child Abuse Review, 13(6), 368-383.

Jackson, T. (1987). Just waiting to die? Cambodian refugees in Thailand. Oxford: Oxfam House.

Keyes, E. (2000). Mental health status in refugees: An integrative review of current research. Issues in Mental Health Nursing, 21(4), 397-410.

Kotchick, B.A., \& Forehand, R. (2002). Putting parenting in perspective: A discussion of the contextual factors that shape parenting practices. Journal of child and family studies, 11, 255-269.

Kreitzer, L. (2002). Liberian refugee women: A qualitative study of their participation in planning camp programmes. International Social Work, 45, 45-58.

Krippendorff, K. (1980). Content Analysis An Introduction to its Methodology. London: Sage.

Krueger, R. A. (1998). Analyzing E Reporting Focus Group Results. Thousand Oaks, CA: Sage.

Krueger, R. A., \& Casey, M. A. (2000). Focus groups: A practical guide for applied research (3rd ed.). Thousand Oaks, CA: Sage.

Leininger, M. (1994). Evaluation criteria and critique in qualitative research studies. In J.M. Morse (Ed.), Critical issues in qualitative research methods (pp. 95-115). Thousand Oaks, CA: Sage. 
Levine, R. A. (1980). A cross-cultural perspective on parenting. In M. D. Fantinit, \& Cardenas, R. (Ed.), Parenting in a multicultural society (pp. 17-40). New York: Longman.

Lewig, K., Arney, F., \& Salveron, M. (2009). Working with refugee families project. Magill, South Australia: Australian Centre for Child Protection, University of South Australia.

Lim, S.-L., \& Lim, B. K. (2004). Parenting style and child outcomes in Chinese and immigrant Chinese families: Current findings and cross-cultural considerations in conceptualization and research. Marriage \& Family Review. Special Issue: Parenting Styles in Diverse Perspectives, 35(3/4), 2143.

Magnuson, K. A., \& Duncan, G. J. (2002). Parents in poverty. In B. Webber (Ed.), Handbook of parenting (Vol. 4, pp. 95-122). Mahwah, New Jersey: Lawrence Erlbaum Associates.

Masten, A. S., \& Reed, M. J. (2002). Resilience in development. In C. R. Snyder, \& Lopez, S. J. (Ed.), Handbook of positive psychology (pp. 74-88). New York: Oxford University Press.

Menjivar, C., \& Salcido, O. (2002). Immigrant women and domestic violence: Common experiences in different countries. Gender $\&$ Society, 16(6), 898-920.

Moran, P., \& Ghate, D. (2005). The effectiveness of parenting support. Children \& Society, 19(4), 329338.

Morse, J.M., Barrett, M., Mayan, M., Olson, K., \& Spiers, J. (2002). Verification Strategies for Establishing Reliability and Validity in Qualitative Research. International Journal of Qualitative Methods, 1, 13-22.

My, T., \& Cuninghame, C. (1996). Focusing on health: focus groups for consulting about health needs. In T. Heller, J. Reynolds, R. Gomm, R. Muston, \& S. Pattison, Mental health matters: A reader (pp. 31-265). London: MacMillan.

Ochocka, J., \& Janzen, R. (2008). Immigrant parenting: A new framework of understanding. Journal of Immigrant \& Refugee Studies, 6(1), 85-111.

Oke, M. (2008). Using narrative methods in cross-cultural research with Mongolian and Australian women survivors of domestic violence. Qualitative Research Journal, 8(1), 2-19.

Patton, M. Q. (2002). Qualitative research and evaluation methods (3rd ed.). New York: Sage.

Paulino, A., \& Burgos-Servedio, J. (1997). Multicultural Perspectives for Working with Immigrant Families in Transition. In E. Congress (Ed.), Multicultural Perspectives for Working with Families. New York: Springer Publishing.

Pine, B. A., \& Drachman, D. (2005). Effective child welfare practice with immigrant and refugee children and their families. Child Welfare, 84(5), 537-562. 
Polit, D. F., \& Hungler, B. P. (1999). Nursing research (6th ed.). Philadelphia: J.B. Lippincott Company.

Pourgourides, C., Sashidharan, S., \& Bracken, P. (1996). A Second Exile: The Mental Health Implications of Detention of Asylum-seekers in the United Kingdom. Northern Birmingham: Mental Health NHS Trust.

Roopnarine, J. L., Krishnakumar, A., Metindogan, A., \& Evans, M. (2006). Links between parenting styles, parent-child academic interaction, parent-school interaction, and early academic skills and social behaviors in young children of English-speaking Caribbean immigrants. Early Childhood Research Quarterly, 21(2), 238-252.

Sidebotham, P. (2001). An ecological approach to child abuse: A creative use of scientific models of research and practice. Child Abuse Review, 10, 97-112.

Stein, B. (1981) The Refugee Experience: Defining the Parameters of a Field of Study, International Migration Review, 15(1), 320-330

Sundhagel, M. (1981). Situation and role of refugee women: Experience and perspectives from Thailand. International Migration Review, 19, 102-107.

Sung, K.-T. (1998). An exploration of actions of filial piety. Journal of Aging Studies, 12(4), 369-386.

Teti, D. M., \& Candelaria, M. A. (2002). Parenting competence. In B. Webber (Ed.), Handbook of parenting (Vol. 4, pp. 149-180). Mahwah, New Jersey: Lawrence Erlbaum Associates.

Tilly, C. (1990). Transplanted networks. In V. Yans-McLaughlin (Ed.), Immigration reconsidered: History, sociology, politics (pp. 79-95). New York: Oxford University Press.

Turton, D. (2003). Conceptualising Forced Migration. University of Oxford: Refugee Studies Centre Working Papers. http://www.rsc.ox.ac.uk/PDFs/workingpaper12.pdf

UNHCR. (2006a). Operational Protection in Camps \& Settlements: A Reference Guide of Good Practices in the Protection of Refugees $\mathcal{E}$ Other Persons of Concern. Geneva: UNHCR.

UNHCR. (2006b). The state of the world's refugees human displacement in the new millennium. Retrieved December 3, 2007 from http://www.unhcr.org/cgibin/texis/vtx/template?page=publ\&src=static/sowr2006/toceng.htm.

van Manen, M. (1990). Basic Content Analysis: Human Science for an Action Sensitive Pedagogy. Ontario: The University of Western Ontario.

Waldron, S. (1987). Blaming the refugees. Refugee Issues, 3, 1-19. 
Watters, C. (1998a). The mental health needs of refugees and asylum seekers: Key issues in research and service development. In F. Nicholson, \& P. Twomey, Current issues in UK asylum law and policy. Ashgate.

Watters, C., (1998b). Mental health services for minority groups and refugees in Europe, MIND/World Federation for Mental Health, London.

Watters, C., (1999). Report of a consultation on the social care and mental health needs of refugees and asylum seekers, Refugee Council, London

Watters, C., (2001). Emerging paradigms in the mental health care of refugees. Social Science $\mathcal{E}$ Medicine, 52(11), 1709-1718.

Weine, S. M., Knafi, K., Feetham, S., Kulauzovic, Y., Klebic A., Sclove, S., Besic, S., Mujagic, A., Muzurovic, J., \& Spahovic, D. (2005). A mixed-methods study of refugee families engaging in multifamily groups. Family Relations, 54, 558-568.

Wilkinson, S. (1998). Focus group in health research: Exploring the meanings of health and illness. Journal of Health Psychology, 3(3), 329-348.

Williams, H. A. (1990). Families in Refugee Camps. Human Organization, 49(2), 100-109.

Williams, N. (2008). Refugee participation in South Australian child protection research: Power, voice, and representation. Family and Consumer Sciences Research Journal, 37(2), 191-209.

Williams, N. (2010). Literature review ecological theory implications for research into the refugee parenting experience. Journal of Child Health Care. 14(1), 1-17.

Wiseman, V. G. B., \& Khan, M. (1995). Labelling in development policy. London: Sage.

Yans-McLaughlin, V. (1990). Introduction. In V. Yans-McLaughlin (Ed.), Immigration reconsidered: History, sociology, and politics (pp. 3-18). New York: Oxford University Press.

Ye-Chin, J. (1980). The refugee experience: A resume. Egham, England: Minority Rights Group.

\section{Author}

Nombasa Williams holds a PhD in Psychology. School of Psychology, Social Work, and Social Policy at the Australian Centre for Child Protection, University of South Australia. Email: Nombasa.Wilkinson@unisa.edu.au 